\section{FRI0057 EVALUATION OF THE IMMUNODOMINANCE OF A HISTONE H4 PEPTIDE IN ANTI-CCP ANTIBODIES FROM RHEUMATOID ARTHRITIS PATIENTS}

L. Rodriguez-Martinez ${ }^{1}$, C. Regueiro ${ }^{1}$, A. Montes ${ }^{1}$, E. Perez-Pampin ${ }^{2}$ A. Mera-Varela ${ }^{2}$, A. Gonzalez ${ }^{1} .{ }^{1}$ Experimental and Observational Rheumatology; ${ }^{2}$ Rheumatology Unit, Instituto Investigacion Sanitaria- H. Clinico Universitario de Santiago, Santiago de Compostela, Spain

Background: The anti-CCP assay identifies antibodies against endogenous citrullinated proteins that are not completely characterized. The histone $\mathrm{H} 4$ seems to be a prominent one according to a recent study (1), which found this protein specifically in the immune complexes from synovial fluid of anti-CCP positive RA patients. Only vimentin, among the previously proposed autoantigens, was present in those immune complexes, but its abundance was much lower than that of histone $\mathrm{H} 4$. In addition, a citrullinated H4-derived peptide, H4-c39/40, showed marked immunodominance since antibodies directed against this peptide were present in $100 \%$ of synovial fluid samples and in $92-94 \%$ of anti-CCP positive sera. These frequencies are much larger than the reported with other autoantigens.

Objectives: To confirm the immunodominance of the $\mathrm{H} 4-\mathrm{c} 39 / 40$ peptide in anti-CCP antibodies from RA patients by direct comparison with citrullinated peptides of two other potential autoantigens.

Methods: Five hundred and thirteen patients with established RA and 273 healthy controls were included. Antibodies against H4-c39/40, cFibB36-52 and cVim6075 were evaluated using indirect ELISA. Concordance between positives and negatives was analyzed with the Goodman and Kruskal's gamma coefficient $(\gamma)$. In addition, Spearman's rank correlation $\left(r_{s}\right)$ was used to analyze the correlation between levels of antibody titers.

Results: In contrast to the previous report (1), only $68.5 \%$ of the anti-CCP positive patients carried anti-H4-c39/40 antibodies. However, this frequency was higher than the observed with the other two peptides, $50.5 \%$ of anti-cFibB36-52 and $28.8 \%$ of anti-cVim60-75 positive patients. Consequently, a high concordance was found between anti-CCP and anti-H4-c39-40 antibodies $(\gamma=0.95)$, which was moderately larger than that observed between anti-CCP and anti-cFibB36-52 antibodies $(\gamma=0.86)$. In addition, anti-H4-c39/40 antibody titers were correlated with anti-CCP titers, but this correlation was similar to the observed between anti-cFibB36-52 and anti-CCP titers $\left(r_{s}=0.34\right.$ and 0.33 , respectively). The anti-cVim60-75 antibodies, in turn, showed notably low concordance and low correlation with the anti-CCP antibodies.

Conclusions: Our results confirm that anti-H4-c39/40 antibodies are a significant component of the antibodies detected with the anti-CCP assay. However, immunodominance of this peptide was not as marked in our patients as the described in the original study.

References:

[1] Meng X, et al. PLoS One. 2016; 11(10):e0165501.

Acknowledgements: Funding was provided by grants of the Instituto de Salud Carlos III (Spain) PI14/01561 and RD12/009/008 with participation of FEDER.

Disclosure of Interest: None declared

DOI: 10.1136/annrheumdis-2017-eular.5739

\section{FRI0058 EFFECT OF MIF GENE HAPLOTYPES ON RHTNF-A AND RHMIF RESPONSE IN PERIPHERAL BLOOD MONONUCLEAR CELLS OF RHEUMATOID ARTHRITIS PATIENTS}

L.A. Hernandez-Palma ${ }^{1}$, S. Garcia-Arellano ${ }^{1}$, S. Cerpa-Cruz ${ }^{2}$, J.F. Muñoz-Valle ${ }^{1} .{ }^{1}$ Research Institute in Biomedical Sciences, University of Guadalajara; ${ }^{2}$ Division of Rheumatology, Guadalajara Civil Hospital "Fray Antonio Alcalde", Guadalajara, Mexico

Background: Macrophage migration inhibitory factor (MIF) is a pro-inflammatory cytokine that plays important role in the development and pathogenesis of rheumatoid arthritis (RA). MIF promotes the expression of cytokines related to RA development, as tumor necrosis factor alpha (TNF- $\alpha$ ), interleukin (IL)-6 and IL-17. Two polymorphisms in the promoter of the MIF gene have been associated with increased production of protein and it has been shown that TNF- $\alpha$ is involved in the regulation of MIF mRNA expression and protein secretion in a dose-dependent manner.

Objectives: To evaluate the effect of MIF gene haplotypes on rhTNF- $\alpha$ and rhMIF response in peripheral blood mononuclear cells (PBMC) of RA patients

Methods: Genotyping was performed for MIF gene haplotypes in 230 RA patients. Cell culture of PBMC from two patients per homozygous haplotype (5G, $6 G$ and 7C) was performed and stimulated with rhTNF- $\alpha$ and rhMIF. Cytokine levels were analyzed by a microsphere-based ELISA method (Bio-Plex ${ }^{\circledR}$ MAGPIX ${ }^{\mathrm{TM}}$ ).

Results: rhTNF- $\alpha$ and rhMIF-induced IL-6, IL-17A and IL-17F secretion in PBMC of RA patients. We observed that PBMC extracted from patients with MIF 7C haplotypes stimulated with rhTNF showed higher secretion of IL-17A and IL-17F than patients with $5 \mathrm{G}$ and $6 \mathrm{G}$ haplotypes. IL-6 production with rhMIF stimulation was more pronounced in the $5 G$ haplotype group than $6 G$ or $7 C$ haplotype groups. Conclusions: rhTNF- $\alpha$ and rhMIF promote differential secretion of IL-6, IL-17A and IL-17F according to MIF haplotypes presence. IL-17A and IL-17F secretion of stimulated PBMC with rhTNF- $\alpha$ are higher in patients with 7C haplotype than non-7C haplotypes. Furthermore, IL-6 levels are higher in PBMC from patients with $5 \mathrm{G}$ haplotype stimulated with MIF than non-5G haplotypes.

\section{References:}

[1] McInnes IB, Buckley CD, Isaacs JD. Cytokines in rheumatoid arthritis - shaping the immunological landscape. Nat Rev Rheumatol 2016;12(1):63-68.

[2] Llamas-Covarrubias MA, Valle Y, Navarro-Hernández RE, Guzmán-Guzmán IP, Ramírez-Dueñas MG, Rangel-Villalobos H, Estrada-Chávez C, Muñoz-Valle JF. Serum levels of macrophage migration inhibitory factor are associated with rheumatoid arthritis course. Rheumatol Int 2012;32(8):2307-2311.

[3] Stojanović I, Cvjetićanin T, Lazaroski S, Stosić-Grujicić S, Miljković D. Macrophage migration inhibitory factor stimulates interleukin-17 expression and production in lymph node cells. Immunology. 2009:126(1):74-83

[4] Gregersen PK y Bucala R. Macrophage migration inhibitory factor, MIF alleles, and the genetics of inflammatory disorders: incorporating disease outcome into the definition of phenotype. Arthritis Rheum. 2003:48(5):1171-6.

[5] Xiong C1, Huang B, Cun Y, Aghdasi BG, Zhou Y. Migration inhibitory factor enhances inflammation via CD74 in cartilage end plates with Modic type 1 changes on MRI. Clin Orthop Relat Res. 2014;472(6):1943-54.

Acknowledgements: This study was supported by funding from the National Council of Science and Technology (CONACYT) Grant \#161749 assigned to JFMV.

Disclosure of Interest: None declared

DOI: 10.1136/annrheumdis-2017-eular.4566

\section{FRI0059 CARDIAC, PULMONARY AND PERIODONTAL DISEASE AS COMORBIDITIES IN TNF-DRIVEN MODELS OF CHRONIC POLYARTHRITIS}

M.C. Denis ${ }^{1}$, L. Ntari ${ }^{2}$, M. Sakkou ${ }^{2}$, P. Chouvardas ${ }^{2}$, A. Prados ${ }^{2}$ G.M.C. Consortium ${ }^{3}$, H. Fuchs ${ }^{3}$, V. Gailus-Durner ${ }^{3}$, M. Hrabě de Angelis ${ }^{3}$, B. Simic ${ }^{4}$, M. Crucet ${ }^{4}$, T.F. Lüscher ${ }^{4}$, K. Mitchell ${ }^{5}$, C. Schwarzwald ${ }^{5}$, N. Karagianni ${ }^{1}$, G. Kollias ${ }^{2,6},{ }^{1}$ Biomedcode Hellas $S A ;{ }^{2}$ Department of Immunology, Biomedical Sciences Research Center (BSRC), "Alexander Fleming", Vari, Greece; ${ }^{3}$ German Mouse Clinic, Institute of Experimental Genetics, Helmholtz Zentrum München, German Research Center for Environmental Health (GmbH), Neuherberg, Germany; ${ }^{4}$ Center for Molecular Cardiology; ${ }^{5}$ Clinic for Equine Internal Medicine, Equine Department Vetsuisse Faculty, University of Zurich, Zurich, Switzerland; ${ }^{6}$ Department of Physiology, School of Medicine, National Kapodistrian University, Athens, Greece

Background: Patients with RA exhibit an increased risk of developing multiple extraarticular pathologies. The link between co-manifested pathologies and RA at the level of common molecular and cellular mechanisms remains to be further elucidated.

Objectives: We aimed to identify comorbidities developing in models of TNFdriven chronic polyarthritis and further explore their aetiopathogenesis.

Methods: Through detailed phenotyping, clinical, histopathological and functional analysis we investigated the development of comorbidities in the Tg197 and $\mathrm{Tnf}^{\Delta \mathrm{ARE} /+}$ mouse models that overexpress respectively human and mouse TNF and develop spontaneous chronic polyarthritis with the concomitant development of Crohn's-like IBD in the case of the Tnf $\triangle \mathrm{ARE} /+$ animals. Targeting mesenchymal origin cells, ex vivo cellular analyses and RNA sequencing expression profiling allowed us to further explore the key cellular instigators of RA related comorbidities. Results: Histopathological evaluation and echocardiography assessment of both arthritis models showed thickening of the aortic valve and cardiac dysfunction characterized by mild decreased fractional shortening, decreased heart rate and increased velocities in ascending aorta hinting towards aortic valve disease. The aortic valve pathology, similarly to arthritis, was ameliorated with anti-TNF treatment. The thickening of the aortic valve leaflets was due to fibrosis which consisted almost entirely of mesenchymal origin Valve Interstitial Cells (VICs). VICs from mutant mice expressed high levels of TNF and exhibited a proliferative and migratory phenotype resembling the activated phenotype of pathogenic Synovial Fibroblasts (SFs) isolated from the joints of the same mice. RNA-seq analysis further supported a significant correlation between pathogenic SFs and VICs highlighting a common cellular mechanism linking RA and aortic valve pathology. Furthermore, we show that TNF deregulation leads to additional RA related comorbidities, as described in human disease, including periodontitis with early onset alveolar bone loss and pulmonary inflammation with mild to severe bronchus-associated lymphoid tissue (BALT).

Conclusions: Similarly to human RA patients, TNF-driven arthritis models develop multiple RA-associated comorbidities, offering novel insights into potential molecular and cellular mechanisms commonly underlying these complex pathologies.

References:

[1] Keffer, J. et al. Transgenic mice expressing human tumour necrosis factor: a predictive genetic model of arthritis. EMBO J. 10, 4025-4031 (1991).

[2] Kontoyiannis, D. et al. Impaired on/off regulation of TNF biosynthesis in mice lacking TNF AU-rich elements: implications for joint and gut-associated immunopathologies. Immunity 10, 387-398 (1999).

[3] Armaka, M. et al. Mesenchymal cell targeting by TNF as a common pathogenic principle in chronic inflammatory joint and intestinal diseases. J. Exp. Med. 205, 331-7 (2008).

Disclosure of Interest: None declared

DOI: 10.1136/annrheumdis-2017-eular.5142 